\title{
Marginalised children and young people with autism spectrum disorders
}

Andrea Brammer, Rob Kennedy and Frances Binns

\section{Overview}

- Collaborative working is necessary to improve the patient experience and quality services for children and young people with autism.

- The major challenges for children and young people with autism spectrum disorders relate to social interactions with people and the environment. These challenges are brought into sharp focus when the child/young person requires health care intervention.

- Reasonable adjustments enable access and inclusion in children's health services and are complemented by multi-agency collaboration thus delivering successful clinical outcomes.

\section{Introduction}

In meeting the needs of children and young people and their families, it is recognised that inequalities in distribution of resources limit the holistic care and development of treatment and support strategies available for children and young people / adults with Autism Spectrum Disorders (ASD). Evidence indicates that this results in patients, with and without a diagnosis of ASD having unmet needs (National Autistic Society, 2014; Kennedy and Binns, 2014; NICE, 2013, 2014).

Autism is a spectrum of developmental disorders characterised by deficits in verbal and emotional communication, social reciprocal interaction with stereotyped, repetitive, or unusual behaviours or interests (Inglese, 2009; Levy et al., 2009; 
Rapin, 2002). Autism is referred to as a spectrum of disorders due to the way in which its manifestations can occur in a variety of combinations and be present in varying degrees of severity (Inglese, 2009). Although the term Autism will be used in this chapter, it also refers to children and young people with Asperger's Syndrome, Pervasive Developmental Disorder and Learning Disabilities as there appears to be a strong correlation between learning disability and co-morbidly occurring as Autism. Although there is a dearth of specific data, it appears that children with learning disabilities may also have a reduced ability to understand new and complex information (DH, 2009). This inability to comprehend complex information is related to limited language skills which reduces the child's ability to report their symptoms or distress, which may be manifested as challenging behaviours (MENCAP, 2004). Autism is an increasingly recognised condition and it is suggested that $1-2$ per cent of the primary school-aged population in the United Kingdom may be effected (Baron-Cohen et al., 2009).

Within this chapter we will explore the complexities of meeting the personalised care, for a child or young person with a diagnosis of Autism. To place this into context, a child's journey using a 'virtual' Radiology Department, focusing upon the patient/family journey, will highlight the inequalities of this diagnostic group of patients.

\section{Diagnosis}

Children and young people with Autistic Spectrum Disorders (ASD) have a range of symptoms, including experiencing increased levels of stress and distress when exposed to highly stimulating situations (Aylott, 2010; Kopecky et al., 2013). Autism 
is a spectrum of developmental disorders characterised by deficits in verbal and emotional communication, social reciprocal interaction with stereotyped, repetitive or unusual behaviours or interests (Inglese, 2009; Levy et al., 2009; Rapin, 2002). Autism is referred to as a spectrum of disorders due to the way in which its manifestations can occur in a variety of combinations and be present in varying degrees of severity (Inglese, 2009). This affects the way in which a child and young person interacts with their surroundings and other people (National Autistic Society, 2014). Prior to the National Service Framework (NSF) 2003 for Autism, children and young people who were suspected of having ASD received fragmented diagnosis and minimal intervention following their diagnosis, let alone continued support. This historically led to children and young people being labelled as 'the naughty child' (Brownson, 2014), due to a lack of multi professional and societal understanding, leading to inequitable delivery of care and support.

A plethora of literature suggests that the prevalence of ASD continues to increase across the world in the second decade of the $21^{\text {st }}$ century (Fujiwara et al., 2011; Chiri and Warfield, 2012; Baron-Cohen et al., 2009) with an estimated rate of 1 in 63 being reported in the United Kingdom (UK) (Baron-Cohen et al., 2009). The ratio of individuals with ASD is reported to be 7:1 male to female (Whiteley et al., 2010) and this is anecdotally experienced in clinical practice. The implication of this increase in diagnosis is that young people (and their families) have a definitive diagnosis of the condition that they are living with, they have limited access to appropriate support and treatment to help them to understand and manage the condition (Baron-Cohen et al., 2009; Couteur et al., 2008). An increase in prevalence of ASD therefore equates to an increase in required resources and associated costs to meet the 
increased needs (Briggs, 2014) yet the cost of heart disease, stroke and cancer combined is less than the health costs of ASD (London School of Economics and Political Science, 2014). Conversely, the amount of money committed to research for ASD is insignificant in comparison ( $£ 6.60$ per person with ASD compared with $£ 295$ per person with cancer). In the current economic climate, with dwindling, pressurised resources available, it can perhaps be seen how inequalities in health become manifest.

\section{Reflection}

How would you know that a child or young person was affected by autism?

Now, think about a child or young person that you have come into contact with; think about how they communicate and interact with the world around them. Consider how this child, with a diagnosis of autism would interact. Do you think that this would impact upon your ability to communicate, or deliver equitable care?

\section{Associated comorbidities of ASD and medical intervention}

Evidence from literature demonstrates the increase in ASD when the associated comorbidities children and young people with ASD report are taken into consideration: for example, sleep problems, epilepsy, gastro intestinal problems, endocrine and many others (Parellada et al., 2013; Tregnago and Cheak-Zamora, 
2012; Goulston et al., 2009; Bultas, 2012; Chiri and Warfield, 2012). The current estimate of 1 in 63 children and adults having ASD, and the subsequent increase in referrals for medical intervention and support, healthcare professionals are increasingly likely to work with children and young people and/or parent and carers with ASD. It is evident that this client group of children, young people and adults are increasing, and therefore there will be an impact upon the delivery of healthcare.

Challenging behaviour may be the only indicator of a medical problem in a child or young person with ASD and this behaviour may not directly correlate with the medical situation (Parellada et al., 2013; Carr and Owen-DeSchryver, 2007). For example, for a child or young person/parent with ASD who does not communicate verbally, identifying the source of a clinical problem is a significant issue. It is therefore imperative that healthcare professionals listen to children, young people and their families who invariably spend a considerable amount of time with their children and are 'experts' in recognising their child's behaviour patterns (Scarpinato et al., 2010).

\section{Economic impact and resources}

Children, young people and adults with ASD frequently have comorbidities associated with the spectrum, such as gastrointestinal, ophthalmological, endocrine, epilepsy, mental health and neurology problems (Bultas, 2012; O'Reilly, 2014) resulting in increased demand for healthcare and an increasing financial pressure on the National Health Service and other supporting organisations. Healthcare is defined as "benefits from health education, disease prevention, diagnosis, treatment, rehabilitation and terminal care" (Wright, Williams and Wilkinson, 1998: 1310). As a 
result, services for children and adults with ASD cost more than several prominent diseases combined; yet proportionally ASD receives a small fraction in funding for research (Briggs, 2014).

\section{Failing to deliver}

Failure to overcome barriers and provide reasonable adjustments for children and young people with ASD equates to discrimination (Hebron, 2011). Evidence indicates the failure of organisations to make adjustments (Bultas, 2012; Goulston et al., 2009) and suggests that it is still not routine practice in the UK to develop reasonable adjustments for patients with ASD despite it being a legal requirement (The National Autistic Society, 2013). The Autism Act (2009) stipulates that healthcare staff working with adult patients with ASD should have specialist training about ASD; it is possible that children are not specified as it is assumed that paediatric teams already have the knowledge and experience to deal with these patients (Walsh and Hall, 2012). The Equality Act (2010) states that public services should make 'reasonable adjustments' for disabled patients in order to improve their care. In addition, several recent reports have highlighted poor practice for vulnerable patients, and have placed responsibility on public sector services to improve quality and patient safety (DoH, 2012; Francis, 2013; Berwick, 2013; Keogh, 2013). These reports state that patients should be involved in decision making about their care.

\section{Equality in accessing healthcare}

Healthcare workers in the National Health Service (NHS) have a moral and ethical obligation to look after patients with ASD, yet reports published such as the Department of Health's report into Winterbourne View Hospital unfortunately 
illustrate that this is not always the case (DoH, 2012). Nevertheless, the media frequently report high profile cases where patients are not receiving the (basic) care that they are entitled to (ITV plc, 2014). Children, young people and adults with ASD are eligible to the same healthcare that the rest of the population is entitled to (Autism Act, 2009; Equality Act, 2010; Health and Social Care Act, 2012). Failure to provide appropriate healthcare to this cohort of patients amounts to discrimination (Autism Act, 2009) and may result in patients having delayed or missed diagnosis which negatively impacts on health outcomes (Rhoades, Scarpa and Salley, 2007).

Brammer (2015) highlights that physicians do not listen to patients' needs (Carbone et al., 2010; Bultas, 2012). Failure to listen to the needs of patients with ASD may result in the patient exhibiting challenging behaviour which in turn may negatively affect the clinical outcome of an investigation or treatment (Van Der Valt and Moran, 2001; Kopecky et al., 2013). Several reports have been published which emphasise to healthcare staff the importance of listening to patients and their carers in a bid to improve not only quality of care delivered to patients but also patient safety (Berwick, 2013; Francis, 2013; Keogh, 2013). Children, young people and adults with ASD have more unmet health needs than the rest of the population (Shieve et al., 2012; Tregnago and Cheak-Zamora, 2012; Chiri and Warfield, 2012). Chiri and Warfield (2012) described unmet needs in the following healthcare services:

- Routine preventative care;

- Specialist care;

- Physical, occupational or speech therapy;

- Mental healthcare or counselling. 
Research findings demonstrate that there are unmet needs in relation to supporting families' with financial problems (Shieve et al., 2012; Tregnago and Cheak-Zamora, 2012). All of these findings originated in the United States, however these may be transferable to the United Kingdom population and consist of:

1. Iow family income or inability to meet the cost of specialist care (Shieve et al., 2012; Tregnago and Cheak-Zamora, 2012) (this phenomenon is unlikely to be reported in the UK due to the NHS and subsequent 'free' provision of services);

2. a delay in care (Shieve et al., 2012; Tregnago and Cheak-Zamora, 2012). This is likely to be reported in the UK due to barriers accessing healthcare.

In the UK it is recognised that 'hard to reach' groups such as homeless people, travellers or refugees (Pfeil and Howe, 2004) exist and frequently do not receive equitable access to healthcare due the very nature of their background.

\section{Access and barriers to health and diagnostic treatments}

Research findings demonstrate that children, young people and their families with ASD reported difficulty accessing healthcare (Parellada et al., 2013; Tregnago and Cheak-Zamora, 2012; Bultas, 2012; Chiri and Warfield, 2012). There are a variety of factors described which contribute to this difficulty: 
- Failure to make reasonable adjustments (Parellada et al., 2013; Tregnago and Cheak-Zamora, 2012).

- Communication difficulties (Parellada et al., 2013).

- Lack of expertise of clinicians (Parellada et al., 2013; Tregnago and CheakZamora, 2012).

In addition to those noted above, barriers to healthcare (Parellada et al., 2013) may consist of:

- long waiting times;

- over stimulating environment;

- lack of time = barrier to provision of primary care;

- high out of pocket expenses/low income;

- timing of appointments;

- child's behaviour/characteristics of ASD;

- bureaucracy/referral problems/ rigidity.

Evidently, accessing routine healthcare treatment can often be complex, challenging, ineffective and costly for the child or young person with ASD. For example, accessing diagnostic images in a Radiology Department relies upon cooperation of the child and support from their family/carers. However, for many children and young people with ASD, the actual process can be fraught (Brammer, 2015). When arriving at the Radiology Department multi-sensory problems may trigger challenging behaviour, including normal everyday situations such as leaving home, getting in a car, visiting an unfamiliar place. When the child with ASD has arrived in the Radiology Department they may then be required to change into a hospital gown. 
Many children and young people with ASD find the movement of clothes across the surface of their skin to be very sensitive and this may also become a barrier to a successful radiology experience (Grandin, 2006a).

Goulston et al. (2009) specifically explored issues within the radiology environment and concluded that in addition to barriers already described, the following phenomena are present:

- Seperation anxiety (the patient is asked to enter the examination room without their parent/carer);

- Inadequate information essential for preparation for the child and young person from their parent/carer;

- Staff attitudes including: lack of understanding of the child's needs; lack of care; 'controlling parent' behaviour of helathcare professionalsencourages anxiety in the child; anticipatory fear of dealing with challenging behaviour.

Goulston et al. (2009) suggest that these problems can be overcome with improved communication with the child and their parent /carer and also with carefully planned preparation. Lai et al. (2012) suggest that all healthcare professionals should have an awareness of ASD as determined by the Autism Act (2009) (Kennedy and Binns, 2014). Within the specific setting of the radiology department, children and young people who are unable to tolerate radiology imaging have the following options:

- Do not have a diagnostic test (Lyon and Reeves, 2006a).

- Immobilisation for the imaging procedure (The Society of Radiographers, 2012). 
- Referral for therapeutic safe holding, sedation or general anaesthetic (chemical restraint) (Nordahl et al., 2008; Khan et al., 2007; Kennedy and Binns, 2016).

- Hospital Play Specialists (HPS) utilised to enable cooperation (Kennedy and Binns, 2016; Pressdee et al., 1997).

\section{Reasonable adjustments}

It is difficult to find a decisive description of 'reasonable adjustments'. However Atkinson (2011) discusses the implications of the Equality Act 2010, the Health and Social Care Act 2012 and the Autism Act 2009 in conjunction with recommendations made in the report 'Healthcare for All' (Michael, 2008) and clearly summarisies what constitutes a 'reasonable adjustment'. In many respects, making reasonable adjustments requires a simple and straightforward approach, placing the child and young person and their family at the centre of everything. It is about them, their child's treatment and how the organisation, or in the case study utilised in this chapter, the Radiology Department can fit in around them and meet their individualised specific needs, not how they 'must' fit in to depertmental ways of working that are often process driven and based upon historical, outdated methods of care delivery.

Atkinson (2011) considers that enhancing co-ordination of healthcare by supporting the use of locally agreed portable portfolios, or 'health passports', which contain a brief outline of a person's health issues and history and which people with learning disabilities can take to healthcare appointments will help in planning, communication and flexibility of care delivery whilst also ensuring that healthcare staff understand 
and apply the principles of mental capacity legislation, including how to promote informed decision making, as well as how to make a decision in a person's best interests when they cannot make their own choices. The availability of autism/learning disability liaison nurses, who support service users, carers and healthcare staff through communication, coordination and the application of specialist knowledge when children and young people attend acute hospitals is key to this. Part of the nurse specialist role would also be to ensure that children and young people can access annual health checks within primary care; awareness training for all staff in healthcare services; providing practical support and information to families and carers and providing information regarding services, health conditions, treatments and important health promotion messages in formats that are more accessible for children and young people with ASD and/or a learning disability; this could include the use of pictures, symbols, easy to follow language and DVDs.

\section{Reasonable adjustments to support equitable access to healthcare}

Some barriers could potentially be overcome by making 'reasonable adjustments' to accommodate children and young people with ASD. For example:

- Bureaucracy could be reduced by improving communication between parents and healthcare providers, planning ahead and by the use of social stories (Aylott, 2010).

- Patient condition issues could be improved by adapting communication methods to suit the child with ASD; listening to parents/carers as to what their childs 'do's and don't's are (Aylott, 2010);

- Environmental problems could be addressed by more time for appointments, more convenient scheduling which suits the child and 
family, the priotisation of children and young people with ASD to avoid lengthy waits, provision of a quite area to avoid over stimulation.

- Healthcare profesional problems could be improved through training, utilising 'Positive about Autism ${ }^{\text {TM' }}$ training and an ASD Champion model (Aylott, 2010; Kennedy and Binns, 2014; Major, et al., 2013;The National Austistic Society, 2014).

The literature stating what reasonable adjustments should be made for children and young people with ASD does not clarify if these adjustments have been discussed with the patient and/or their family/carers and it can be argued that healthcare professionals have assumed what reasonable adjustments should be made. This assumption should be tested by evaluating the impact of reasonable adjustments on access to healthcare for children, young people, adults and families with ASD.

\section{Person Centred Needs Assessments (PCNA)}

Health needs assessments emerged following reforms to the NHS in the 1990s (Wright et al. 1998) as an evidence based tool to deliver equitable and efficient healthcare being available for all, at a time when resources were becoming limited and members of the public were becoming more active in expressing their views about quality of service. Wright et al. (1998) state that identified health needs should be met with effective intervention, maintaining that there is an overlap with 'need', 'demand' and 'supply'. Health needs assessments are an opportunity to identify areas of unmet needs and to develop strategies to overcome these (Wright et al. 1998). One important aspect of health needs assessments is the epidemiology of the disease (Williams and Wright, 1998) in order to develop strategies to cope with 
specific ailments and many needs assessments were developed for populations of people (Wilkinson and Murray, 1998) with assessments being carried out at various levels.

In the $21^{\text {st }}$ century, needs assessments have become more 'person centred' in their approach (National Disability Authority, 2012); identifying what actions are required in order for the child to achieve a specific goal and this is recognisable in the person centred needs assessment (PCNA). Discussion in 1998, surrounding PCNA, debated the dilemma of which individuals had a greater health need in order to compete for limited resources (Stevens and Gillam, 1998) and were generally completed by medical staff to fight for individual cases, rather than to identify the quality of the hospital experience from the perspective of the child and family. Evaluation of health needs assessments to identify gaps in care was also deemed to be important (Wilkinson and Murray, 1998).

\section{Case study 1: David}

David, a 10 year old boy with ASD, was referred to the local hospital for radiographic exploration prior to having surgery to correct his kyphoscoliosis (curvature of the spine). His parents were both extremely anxious before attending the hospital as he had no previous experience of being an inpatient. David finds other life situations challenging due to his sensory processing disorder and limited mobility. The spinal surgeon informed his David's parents during his outpatient consultation that he will require a pre-operative blood test and a further $\mathrm{x}$-ray of his spine. He would also need to have a general anaesthetic for the spinal surgery. 
As a health care practitioner, how could you:

1. Prepare David for his admission and diagnostic tests?

2. Prepare his parents/carers for the admission?

3. Prepare the environment that David is in?

4. In addition, what do you think are the family's support needs?

5. How would you know that you were listening and getting it right? Now consider the case study below.

\section{Case Study 2: Reflections from a member of staff involved in delivering support to a young person with Autism.}

"Rizwan arrived at the x-ray department for his appointment with his mum, dad, sibling and myself as his care support worker. The waiting area was very busy due to the Scoliosis clinic running. Nita (Rizwan's mum) informed me that it is always a very busy clinic. I asked the radiographers at the time how long it would be before Rizwan could be seen for his x-ray. I was informed that due to the number of patients waiting and the severity of some of the cases they had to be seen first.

Rizwan appeared to be 'ok' for the first fifteen minutes after we arrived in the waiting area but soon became over stimulated, due to the high levels of noise and strange people. I suggested to his mother Nita that they could wait in the Ultrasound waiting area as there was nobody there, but this was going against the preparation that Rizwan had been shown, and would have upset him more. Due to 
the nature of the clinic and being unsure who was doing the $\mathrm{x}$-rays it was difficult to be able to pass on relevant information about Rizwan's needs. I advised two of the radiographers not to speak to Rizwan as unfamiliar voices and faces often caused him to become very agitated and upset and to instruct mum what needed to happen. I also confirmed that the lights could be left on for Rizwan for his x-ray as I knew he did not like the dark.

After an hour and a half of waiting, Rizwan could go into the x-ray room. I made sure that the room was as it was in the photographs Rizwan had been using, the Thomas the Tank video was also playing. Nita was anxious, as he had become over stimulated by this point, and it was going to be very difficult to get him in the room and to settle him when he was in the room.

Nita brought him down to the room, as two radiographers went into the room I waited outside the room. Rizwan was highly anxious by this point and did not want to be in the room. He attempted to bite one of the radiographers. The radiographer came out of the room after approximately 10 minutes, to allow some time for mum to try and calm Rizwan, but this was unsuccessful. Although he had approximately a 15 minute appointment, due to other patients waiting to be seen there was not the time for him to be able to acclimatise to the room. Also heightened by the length of waiting time, Rizwan's anxiety levels were too high for him to be able to take everything in.

Nita suggested that it would be appropriate for Rizwan to be able to attend the department outside the Scoliosis clinic times at a quieter time to be able to 
accommodate his needs. Nita felt the preparation had been a waste of time. Nita felt that it would be more difficult for him to come back as it would become a game to Rizwan therefore becoming more difficult to gain his co-operation for the x-ray. Afterwards Nita said that "she was unhappy he could not be seen straight away and that his needs were not taken into account."

Nita made a formal complaint.

\section{Reflection:}

1. Can you identify what went wrong?

2. Can you indicate any reasonable adjustments required to meet Rizwan's specific interests and needs?

\section{Transition to adult services}

With increased prevalence of ASD it follows that there will be an increasing number of children and young people moving into adult services (Parellada et al., 2013;

Shieve et al., 2012; Bultas, 2012 ;Lai et al., 2012; Chiri and Warfield, 2012).

Transition into adult services is a complex and confusing process involving families (Watson et al., 2011; Colver et al., 2013) and healthcare workers in the paediatric and adult field, requiring robust strategies to deal with the process (Hamdani, Jetha and Norman, 2011). Transition typically occurs between the ages of 16 and 18 years (Watson et al., 2011). However, there is evidence of extending this age range to 
between 14 and 25 years (Watson et al., 2011). Failure to transfer to adult services may result in unmet health needs (Stevenson et al., 1997; Watson, 2000; Nakhla et al., 2009; Colver et al., 2013) as there are no transition models for children and young people with ASD (Watson et al., 2011; Hamdani et al., 2011; Colver et al., 2013; Cheak-Zamora et al., 2014). There are suggestions that it should be a holistic approach (Colver et al., 2013). Paucity of transition models for children with ASD may be due to a lack of identified need and lack of availability of adult services (Department of Health, 2006b, 2010; Singh et al., 2010).

To complicate the matter of transition further, definitions of adolescence vary between 10/12-19 years (World Health Organisation, 2015) and 10-19 years old (UNICEF, 2011) with additional definitions of youth and young people extending until the age of 24 (World Health Organisation, 2015; UNICEF, 2011; Colver et al., 2013). Additionally, improvements in healthcare resulted in improved lifespan expectances of children with disabilities causing an increased need for adult healthcare services as they were no longer eligible for paediatric care (Hamdani et al., 2011) which consequently led to unmet health needs.

Many healthcare providers accept children up to the age of 16 years, yet in April 2015 , a paediatric surgeon at a local children's hospital divulged that he is frequently asked to accept 19 year olds as new patients for surgery due to advances in medicine resulting in patients, who a few years ago would not have been expected to survive childhood, now surviving and needing continued care. The adult teams, having not dealt with this cohort of patients, do not have the skills and competences to look after these patients. This correlates with evidence regarding lack of 
availability of adult services for this cohort of patients (Department of Health, 2006b, 2010; Singh et al., 2010).

\section{Conclusion}

In summary, it is unequivocal that there is an increase in the prevalence of ASD, and the associated comorbidities result in an increase in the numbers of children and young people with ASD accessing healthcare. It is also well evidenced that children and young people with ASD struggle to tolerate the healthcare environment without demonstrating challenging behaviour which may negatively impact on the success of their treatment. Evidence also suggests that patients with ASD have problems accessing healthcare in the first place, and have more unmet needs. In order to ensure that patients with ASD are able to receive the healthcare that they are entitiled to, it is necessary, and a legal requirement, to provide reasonable adjustments whilst at the same time complying with legislation ensuring the rights of the patient are maintained.

It has been demonstrated that some organistations are making reasonable adjustments for children and young people with ASD and there is literature which attempts to identify how access to healthcare can be improved for those with ASD. Brammer (2015) demonstrates that in order to deliver clinically effective and truly inclusive healthcare for all children and young people and their families with ASD the following recommendations must be followed:

- Completion of individual needs assessment by all healthcare teams on admission to all areas of the health care practice. 
- Implementation of personalised reasonable adjustments for children and young people with ASD.

- Provision of quiet areas for children and young adults with ASD in all settings

- Mandatory autism training for all staff working with children, young people and adults with ASD.

- Improved use of communication tools for all individuals with ASD.

- All environments should consider the model illustrated in figure 10 for working with children with ASD.

- Communicating with and learning from each other locally and nationally to improve quality of care to children and young people with ASD and their families.

Anecdotal evidence suggests that there remains a culture in some areas where medical staff and healthcare professionals are resistant to change and insist that they do not need to adjust their behaviour. This would appear to contradict the suggestion that children and young people's services have the knowledge and skills to deal with children and young people with ASD (Walsh and Hall, 2012). This approach frequently results in the child and family with ASD not receiving the treatment they attended for; invariably, once these areas experience an untoward clinical incident with a patient with ASD they become activists for change.

\section{Further reading}


- Kennedy, R. and Binns, F. (2014) Communicating and managing children and young people with autism and extensive burn injury. Wounds UK, 10 (3).

- Page, A., Mcdonnell, A., Gayson, C., Moss, F., Mohammed, N., Smith, C. and Vanes, N. (2015) Clinical holding with children who display behaviours that challenge. British Journal of Nursing, 24(21): 1086-93.

- Vaz, I. (2013) Visual symbols in healthcare settings for children with learning disabilities and autism spectrum disorder. British Journal of Nursing , 22 (3): 156-159.

\section{Relevant web links}

http://www.autism.org.uk/

http://www.positiveaboutautism.co.uk/

http://www.cmft.nhs.uk/childrens-hospitals/our-services/services-for-children-withautism

http://www.cafamily.org.uk/

\section{References}

Atkinson, D.T.B. (2011) Improving health outcomes for people with learning disabilities. Nursing Standard, 26 (6): 33-26. 
Autism Act 2009. London: The Stationery Office Limited.

Aylott, J. (2010) Improving access to health and social care for people with autism. Nursing Standard , 24 (27): 47-56.

Baron-Cohen, S., Scott, F.J., Allison, C., Williams, J., Bolton, P., Matthews, F.E., et al. (2009) Prevalence of autism-spectrum conditions: UK school-based population study. The British Journal of Psychiatry, 194: 500-509.

Brammer. A (2015) A service evaluation of the impact of person centred needs assessments for patients with Autism-Spectrum Disorder (ASD) prior to attending the Radiology Department. University of Bolton.

Brownson. D (2014) He's Not Naughty! A Children's Guide to Autism: Bodhi Book Press Ltd.

Berwick, D., 2013. A promise to learn - a commitment to act; Improving the Safety of Patients in England, London: Williams Lea.

Briggs, H. (2014) Autism costs '£32bn per year' in UK. Available at: http://www.bbc.co.uk/news/health-27742716?print=true (accesed 5 February 2016). Carbone, P. S., Behl, D. D. \& Azor, V., 2010. The Medical Home for Children with Autism Spectrum Disorder: Parent and Pediatrician Perspectives. Journal of Autism Developmental Disorder, Volume 40, pp. 317-324. Available from: http://web.b.ebscohost.com/ [Accessed 5 November 2014].

Carr, E.G., and Owen-DeSchryver, J.S. (2007) Physical Illness, Pain, and Problem Behaviour in Minimally Verbal People with Development Disabilities. Journal of Autism Development Disorder, 37: 413-424.

Centers for Disease Control and Prevention (2014) National Survey of Children with Special Health Care Needs. Available at: http://www.cdc.gov/nchs/slaits/cshcn.htm (accessed 8 February 2016). 
Charman, T. and Gotham, K. (2013) Measurement Issues: Screening and diagnostic instruments for autism spectrum disorders - lessons from research and practise. Child and Adolescent Mental Health, 18(1): 52-64.

Cheak-Zamora, N.C., Farmer, J.E., Mayfield, W.A., Clark, M.J., and Marvin, A.R. (2014) Health Care Transition Services for Youth With Autism Spectrum Disorders. Rehabilitation Psychology, 59 (3): 340-348.

Chebuhar, A., McCarthy, A. M., Bosch, J., and Baker, S. (2013) Using Picture Schedules in Medical Settings for Patients With an Autism Spectrum Disorder. Journal of Pediatric Nursing, 28: 125-134.

Chiang, H.-M. (2008) Expressive communication of children with autism: the use of challenging behaviour. Journal of Intellectual Disability Research, 52 (11): 966-972. Chiri, G. and Warfield, M. E. (2012) Unmet Need and Problems Accessing Core Health Care Services for Children with Autism Spectrum Disorder. Maternal Child Health, 16: 1081-1091.

Colver, A. F., Merrick, H., Deverill, M., Le Couteur, A., Parr, J., Pearce, M.S., et al. (2013) Study protocol: longitudinal study of the transition of young people with complex health needs from child to adult health services. BMC Public Health, 13. Couteur, A.L., Haden, G., Hammal, D. and McConachie, H. (2008) Diagnosing Autism Spectrum Disorders in Pre-school Children. Journal of Autism Development Disorder Using Two Standardised Assessment Instruments: The ADI-R and the ADOS, 38: 362-372.

Dearlove, O. and Corcoran, J.P. (2007) Sedation of children undergoing magnetic resonance imaging. British Journal of Anaesthesia, 98 (4): 548-549.

Department of Health (2012) Department of Health Review: Winterbourne View Hospital Interim Report . London: Department of Health. 
Department of Health (2006a) Better services for people with an Autistic Spectrum Disorder. Available at:

http://webarchive.nationalarchives.gov.uk/20130107105354/http://www.dh.gov.uk/pr od_consum_dh/groups/dh_digitalassets/@dh/@en/documents/digitalasset/dh_0652 38.pdf (accessed 9 February 2016).

Department of Health (2006b) Transition: Getting it right for young people. Available at:

http://webarchive.nationalarchives.gov.uk/20130107105354/http:/www.dh.gov.uk/pro d_consum_dh/groups/dh_digitalassets/@dh/@en/documents/digitalasset/dh_41321 49.pdf (accessed 9 February 2016).

Department of Health (2008) High Quality Care for All. Available at: http://webarchive.nationalarchives.gov.uk/+/www.dh.gov.uk/en/Healthcare/Highqualit ycareforall/index.htm (accessed 9 February 2016).

Department of Health (2010) 'Fulfilling and rewarding lives'. The strategy for adults with autism in England. London: Department of Health.

Francis, R. (2013) Report of the Mid Staffordshire NHS Foundation Trust Public Inquiry. London: The Stationary Office.

Grandin, T. (2006a) Thinking in Pictures: And Other Reports from My Life with Autism (2nd edn). London: Doubleday.

Department of Health (2012) Winterbourne View Summary of the Government Response. London: Department of Health.

Guthrie, W., Swineford, L.B., Nottke, C. and Wetherby, A.M. (2013) Early diagnosis of autism spectrum disorder: stability and change in clinical diagnosis and symptom presentation. The Journal of Child Psychology and Psychiatry, 54 (5): 582-590. 
Hamdani, Y., Jetha, A. and Norman, C. (2011) Systems thinking perspectives applied to healthcare tranistion for youth with disabilities: a paradigm shift for practice, policy and research. Child: care, health and development, 37 (6): 806-814. Hamdani, Y., Jetha, A. and Norman, C. (2011) Systems thinking perspectives applied to healthcare transition for youth wth idisabilities: a paradigm shift for practice, policy and research. Child: Care, Health and Development, 37 (6): 806-814. Harvey-Lloyd, J.M. (2013) Operating within the legal and ethical framework to gain co-operation when imaging paediatric patients. Radiography, 19:285-289. Health and Social Care Act (2012), c.7. London: The Stationery Office Limited Healthcare Commission (2007) An improving picture? Imaging services in acute and specialist trusts. London: Commission for Healthcare Audit and Inspection.

Hebron, C. (2011) Developing tools to enable easier access to mainstream services. Learning Disability Practice, 14 (9): 22-26.

Inglese, M.D., (2009) Caring for children with autism spectrum disorder part ii: screening, diagnosis and management. Journal of Pediatric Nursing, 24:1: 49-59. ITV Plc (2014) Chief inspector of hospitals: Failing hospitals 'need more help'. Available at: http://www.itv.com/news/granada/update/2014-08-04/chief-inspector-ofhospitals-failing-hospitals-need-more-help/ (accessed 5 February 2016).

Kennedy, R. and Binns, F. (2014) Communicating and managing children and young people with autism and extensive burn injury. Wounds UK, 10(3): 60-65. Keogh, B. (2013) Review into the quality of care and treatment provided by 14 hospital trusts in England: overview report. Available at: http://www.nhs.uk/nhsengland/bruce-keogh-review/documents/outcomes/keoghreview-final-report.pdf (accessd 5 February 2016). 
Keogh, B. (2013) Review into the quality of care and treatment provided by 14 hospital trusts in England: overview report. Redditch: NHS England.

Khan, J. J. et al., 2007. A program to decrease the need for pediatric sedation for CT and MRI. Applied Radiology, 36(4), pp. 30-33. Available from:

http://web.b.ebscohost.com/ [Accessed 16 December 2014].

Kohn, C. (2014) Sensory Overload. Available at:

http://craigkohntheaspergerscoach.blogspot.co.il/ (accessed 5 February 2016).

Kopecky, K., Broder-Fingert, S., lannuzzi, D. and Connors, S. (2013) The Needs of Hospitalized Patients With Autism Spectrum Disorders: A Parent Survey. Clinical Pediatrics, 52(7): 652-660.

Lai, B., Milano, M., Roberts, M. W. and Hooper, S. R. (2012) Unmet Dental Needs and Barriers to Dental Care Among Children with Autism Spectrum Disorders. Journal of Autism Development Disorder, 42: 1294-1303.

Levy, S.E., Giarelli, E., Lee, L.C., Shieve, L.A., Kirby, R.S. Cunniff, C., Rice. C. (2010) Autism spectrum disorder and co-occurring developmental, psychiatric and medical conditions among multiple populations of the United States. Journal of Developmental and Behavioural Pediatrics, 4: 267-274.

London School of Economics and Political Science. (2014) Autism is the most costly medical condition in the UK. Available at:

http://www.Ise.ac.uk/newsAndMedia/news/archives/2014/06/Autism.aspx (accessed 5 February 2016).

Lyon, R. and Reeves, P.J. (2006a) An investigation into why patients do not attend for out-patient radiology appointments. Radiography, 12: 283-290. 
Major, N. E. et al., 2013. Autism Training in Pediatric Residency: Evaluation of a Case-Based Curriculum. Journal of Autism Developmental Disorder, Volume 43, p. 1171-1177. Available from: http:// ebscohost.com [Accessed 29 December 2014].

Manikiza, J., Jones, C., James, T. and Robinson, S. (2010) Autistic Spectrum Disorders; Primary Healthcare Settings. Cardiff: Welsh Assembly Government. MedicineNet.com (2015) Definition of Atypical. Available at: http://www.medicinenet.com/script/main/art.asp?articlekey=9825 (accessed 5 February 2016).

Memari, A.H., Ziaee, V., Mirfazeli, F.S. and Kordi, R. (2012) Investigation of Autism Comorbidities and Associations in a School-Based Community Sample. Journal of Child and Adolescent Psychiatric Nursing, 25: 84-90.

Michael, J. (2008) Healthcare for all: Report of the Independent Inquiry into Access to Healthcare for People with Learning Disabilities. London: Aldridge Press. NICE (2013) Autism in under 19's: support and management. National Institute for Clinical Excellence Guideline CG170. London: NICE. NICE (2015) Challenging behaviour and learning disabilities: prevention and interventions for people with learning disabilities whose behaviour challenges. National Institute for Clinical Excellence, Guideline NG11. London: NICE. Nakhla, M., Daneman, D., To, T., Paradis, G. and Guttman, A. (2009) Transition to adult care for youths with diabetes mellitus: findings from a universal health care system. Pediatrics, 124 (6): 1134-1141.

National Autistic Society (2014) Autism and Asperger syndrome: an introduction. Available at: http://www.autism.org.uk/about/what-is.aspx (accessed 5 February 2016). 
National Disability Authority (2012) So what is 'person centred planning'? Definition and brief history. Availablae at: http://nda.ie/Good-practice/Guidelines/Guidelines-onPerson-Centered-Planning/Guidelines-on-Person-Centred-Planning-formatversions/2-What-is-Person-Centred-Planning-/ (accessed 5 February 2016). Newdick, C. (2005) Who should we treat? Rights, Rationing, and Resources in the NHS (2nd edn). Oxford: Oxford University Press.

NHS Choices (2015) Scoliosis. Available at:

http://www.nhs.uk/conditions/scoliosis/pages/introduction.aspx (accessed 5 February 2016).

O'Reilly, R. (2014) Improving the management of patients with autism. Imaging therapy and Practice, 16-21.

Nordahl, C. W. et al., 2008. Brief Report: Methods for Acquiring Structural MRI Data in Very Young Children with Autism Without the Use of Sedation. Journal of Autism Development Disorder, Volume 38, p. 1581-1590. Available from: http:// ebscohost.com [Accessed 16 December 2014].

Parellada, M., Boada, L., Moreno, C., Llorente, C., Romo, J., Muela, C., et al. (2013) Speciality Care Programme for autism spectrum disorders in an urban population: A case-management model for health care delivery in an ASD population. European Psychiatry, 28: 102-109.

Pfeil, M. and Howe, A. (2004) Ensuring primary care reaches the 'hard to reach'. Quality in Primary Care, 12: 185-90.

Positive About Autism ${ }^{\mathrm{TM}}$ (2014) Positive About Autism ${ }^{\mathrm{TM}}$. Available at: http://positiveaboutautism.co.uk/ (accessed 5 February 2016). 
Rhoades, R. A., Scarpa, A. and Salley, B. (2007) The importance of physician knowledge of autism spectrum disorder: results of a parent survey. BMC Pediatrics , 37 (7): PAGES.

Romanczyk, R.G., Gillis, J.M., Noyes-Grosser, D.M., Holland, J.P., Holland, C.L. and Lyons, D. (2005) Clinical Clues, Developmental Milestones, and Early Identification/Assessment of Children With Disabilities; Practicle Applications and Conceptual Considerations. Infants and Young Children, 18 (3): 212-221.

Samtani, A., Sterling-Levis, K., Scholten, R., Woolfenden, S., Hooft, L., and Williams, K. (2011) Diagnostic tests for Autism Spectrum Disorders (ASD) in preschool children (Protocol). The Cochrane Collaboration.

Scarpinato, N., Bradley, J., Kurbjun, K., Bateman, X., Holtzer, B. and Ely, B. (2010) Caring for the Child With and Autism Spectrum Disorder in the Acute Setting. Journal for Specialists in Pediatric Nursing, 15 (3): 244-254.

Shieve, L.A., Gonzalez, V., Boulet, S.L., Visser, S.N., Rice, C.E., Braun, K.V., et al. (2012) Concurrent medical conditions and health care use and needs among children with learning and behavioural development disabilities, National Health Interview Survey, 2006a-2010. Research in Developmental Disabilities , 33: 467476.

Singh, S.P., Paul, M., Ford, T., Kramer, T., Weaver, T., McLaren, S., et al. (2010) Process, outcome and experience of transition from child to adult mental healthcare: multiperspective study. The British Journal of Psychiatry , 197, 305-312.

Stevens, A., and Gillam, A. (1998). Needs Assessment: from theory to practice. British Medical Journal, 316: 1448-1452. 
Stevenson, C.J., Pharoah, P.O. and Stevenson, R. (1997) Cerebral palsy - the transition from youth to adulthood. Developmental Medicine and Child Neurology, 39: 336-342.

The National Autistic Society (2015) Health workers: everything you need to know. Available at: http://www.autism.org.uk/professionals/health-workers.aspx (accessed 5 February 2016).

The National Autistic Society (2013) Push for action; We need to turn the Autism Act into action. London: The National Autistic Society.

The National Autistic Society (2015) Social stories: their uses and benefits. Available at: http://www.autism.org.uk/living-with-autism/strategies-and-approaches/socialstories-and-comic-strip-conversations/social-stories-their-uses-and-benefits.aspx (accessed 5 February 2016).

Tregnago, M. and Cheak-Zamora, N.C. (2012) Systematic review of disparities in health care for individuals with autism spectrum disorders in the United States. Research in Autism Spectrum Disorders, 6: 1023-1031. UNICEF (2011) The State of the World's Children 2011. New York: United Nations Children's Fund.

United Nations (1989) The convention on the rights of the child. New York: United Nations General Assembly.

Van Der Valt, J.H. and Moran, C. (2001) An audit of perioperative management of autistic children. Paediatric Anaesthesia, 11(4): 401-408.

Vaz, I. (2013) Visual symbols in healthcare settings for children with learning disabilities and autism spectrum disorder. British Journal of Nursing, 22(3): 156-159. 
Walsh, N. and Hall, I. (2012) The Autism Strategy: implications for people with austism and for service development. Advances in mental health and intellectual disabilities, 6(3): 113-120.

Watson, A. R., 2000. Non-compliance and transfer from paediatric to adult transplant unit. Pediatric Nephrology, Volume 14, pp. 469-472. Available from: http://search.proquest.com/ [Accessed 22 May 2015].

Watson, R., Parr, J.R., Joyce, C., May, C. and Le Couteur, A.S. (2011) Models of ransitional care for young people with complex health needs: a scoping review. Child: care, health and development, 37(6): 780-791.

Whiteley, P., Todd, L., Carr, K. and Shattock, P. (2010) Gender Ratios in Autism, Asperger Syndrome and Autism Spectrum Disorder. Autism insights, 2: 17-24.

Widgit Software (2012) Hospital Procedures. Available at:

http://www.widgit.com/resources/health/hospital_procedures/Child_Daycase_Operati on_Flashcards.pdf (accessed 5 February 2016).

Wilkinson, J.R. and Murray, S.A. (1998) Health needs assessment: Assessment in primary care: practicle issues and possible approaches. British Medical Journal, 316: 1524-1528.

Williams, R. and Wright, J. (1998) Epidemiological issues in health needs assessments. British Medical Journal, 316: 1379-1382.

World Health Organisation (2015) Maternal, newborn, child and adolescent health. Available at:

http://www.who.int/maternal_child_adolescent/topics/adolescence/dev/en/ (accessd 5 February 2016). 
Wright, J., Williams, R. and Wilkinson, J.R. (1998) Development and importance of health needs assessment. British Medical Journal, 316: 1310-1313. 